\title{
Incarceration of Spinal Nerve Root through Incidental Durotomy as a Cause of Sciatica
}

\section{Young-Jin Kim}

Department of Neurosurgery, Dankook University College of Medicine, Cheonan, Korea

\section{Corresponding Author:}

Young-Jin Kim

Department of Neurosurgery,

Dankook University College of Medicine, 119 Dandae-ro, Dongnam-gu, Cheonan 31116, Korea

Tel: +82-41-550-6280

Fax: +82-41-552-6870

E-mail: spine1225@naver.com

Received: July 4, 2017

Revised: September 6, 2017

Accepted: September 8, 2017
Copyright (C) 2017 by The Korean Spinal Neurosurgery Society

This is an open access article distributed under the terms of the Creative Commons Attribution Non-Commercial License (http://creativecommons.org/licenses/bync/4.0/) which permits unrestricted noncommercial use, distribution, and reproduction in any medium, provided the original work is properly cited.

Incidental durotomies are a frequent complication during spinal surgery. Cerebrospinal fluid (CSF) leakage from a dural tear may be visually apparent intraoperatively, but occasionally, a tear may not be recognized during the procedure. We report our experience in 2 cases of postoperative incarceration of nerve root as a cause of sciatica, without CSF leakage intraoperatively. When durotomy attributable to surgical manipulation does occur, intraoperative identification is mandated. If a patient develops unexplainable postoperative pain and neurological deficits after lumbar discectomy, incarceration of nerve root should be considered in the differential diagnosis.

Key Words: Incidental durotomy, Sciatica, Cerebrospinal fluid leakage

\section{INTRODUCTION}

Dural tearing is not an uncommon complication during lumbar surgery ${ }^{2,12)}$. It mostly can be detected during surgery and repaired easily. However, incidental durotomy without visible dural tear and leakage of cerebrospinal fluid (CSF) can not be readily found intraoperatively. If once incidental durotomy occur, it is able for nerve root to be entrapped. In this article, we report 2 cases of incarceration of spinal nerve root through incidental durotomy and discuss its possible mechanism.

\section{Case Reports}

\section{Case 1}

This 43-years-old woman was suffered from progressive left-sided sciatic pain for 6 weeks. Neurological examination demonstrated no motor deficits. Magnetic resonance imaging (MRI) revealed a paracentral disc herniation at the L4-L5 level on the left side. The patient underwent partial hemilaminectomy and discectomy. The herniated disc material was identified and removed. The operative procedure was uneventful. Either dura tearing or CSF leakage did not detected on microscope. The patient improved and no neurological deficits were noted. At over 3 months, sudden onset of severe sciatica and weakness of the left foot was occurred. MRI revealed disc herniation and fibrocystic granulation tissue (Fig. 1). The patient was scheduled for a second operation. The pre- vious laminectomy at L4 was extended. The disc herniation did not recur, but ventral dural tear was seen and nerve root was incarcerated through dura tearing (Figs. 2, 3). After subtotal laminectomy, dorsal dura was opened. The intradural disc was seen in the thecal sac. In addition to removal of intradural disc material, the nerve root was repositioned and dura was repaired. She had prompt recovery soon after the surgery with complete resolution of the pain. And the weakness of the left foot subsided slowly.

\section{Case 2}

This 61-year-old woman presented with recurrent bouts pain on low back and right leg over the course of 2 months. Neurological examination demonstrated no sensory or motor deficits. MRI revealed a paracentral disc herniation at the L3-L4 level on the right side. She underwent L3-L4 discectomy. After removal of the inferior third of the superior lamina and superior third of the inferior lamina, extruded disc material was extirpated. The operative procedure was uncomplicated on microscope. There was no visible dural tear and no CSF leak. Her symptoms were relieved until the third postoperative day. The patient complained of progressive severe radiating pain. MRI revealed minimal fluid collection at the same disc space without something wrong (Fig. 4). Because of impending cauda equina syndrome, exploration had to be done. At operative field, ventral dural tearing and incarceration of edematous nerve root were noted (Fig. 5). Following 

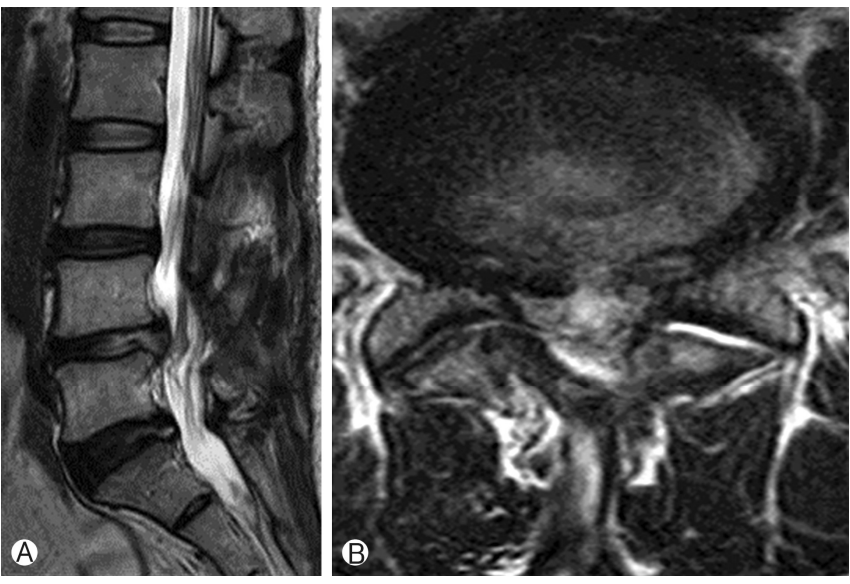

Fig. 1. (A) Midsagittal magnetic resonance (MR) image. (B) Transverse MR image. Magnetic resonance T2-weighted image of case 1 shows a suspicious intradural disc material.

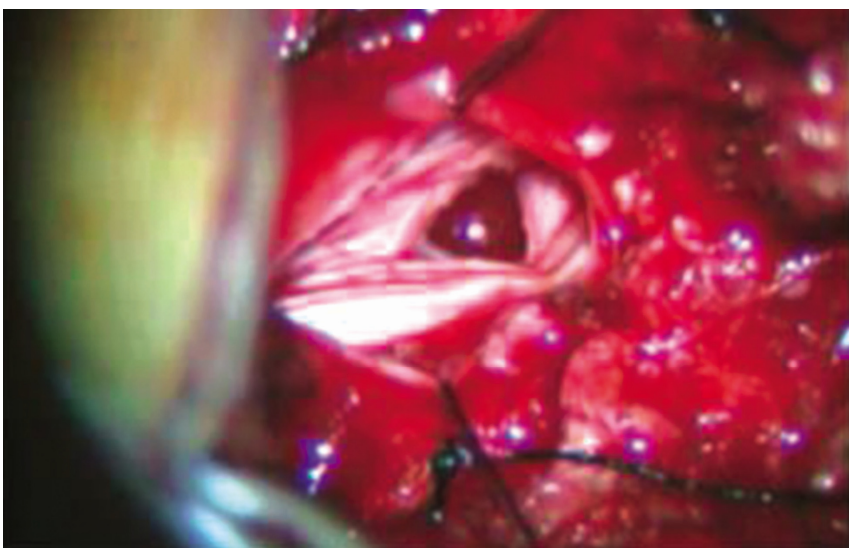

Fig. 2. Intraoperative photography is showing nerve root herniation through a dural defect (case 1).

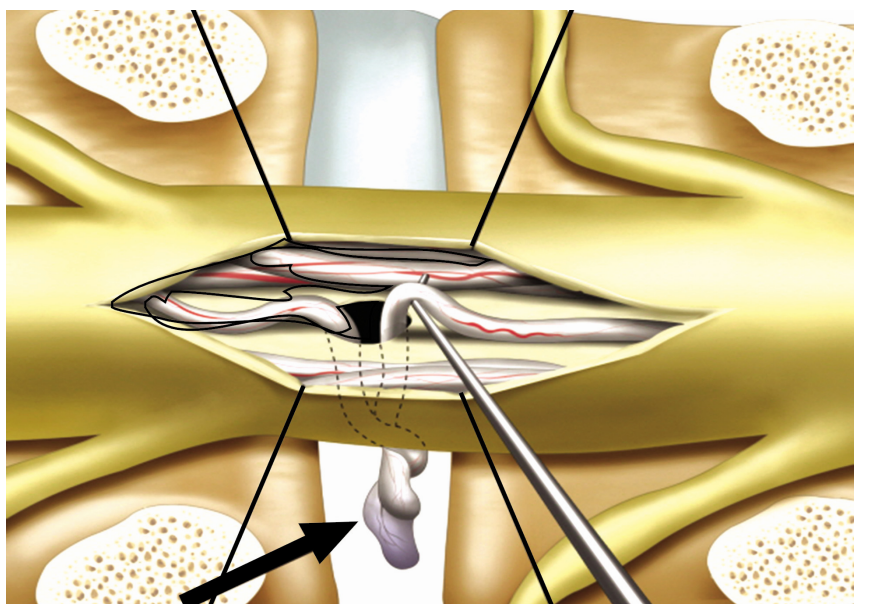

Fig. 3. Schematic picture of nerve incarceration (Black arrow indicates nerve incarceration through defect). Nerve root falls into incidental defect and interlaces itself (Laminar and pedicle are removed only in picture to show inside).

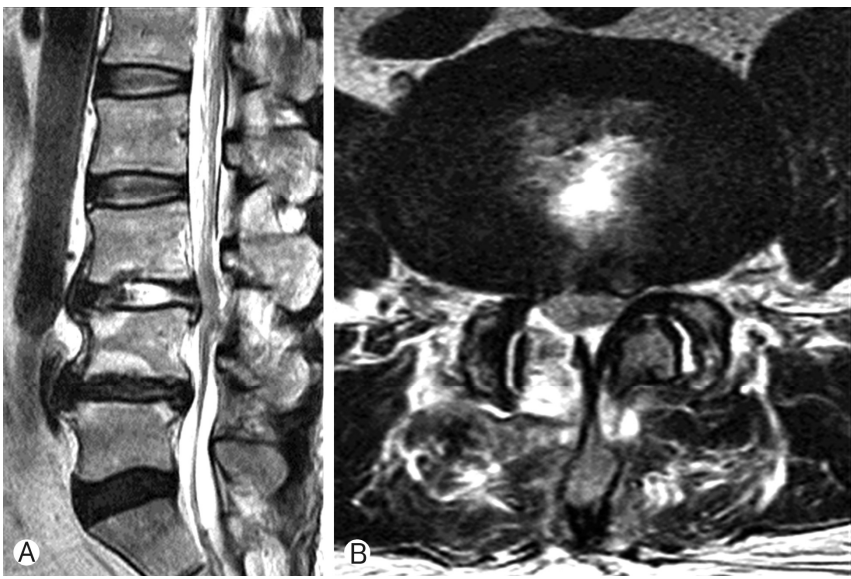

Fig. 4. (A) Midsagittal magnetic resonance (MR) image. (B) Transverse MR image. Magnetic resonance T2-weighted image of case 2 shows forming cerebrospinal fluid puddle in the disc space.

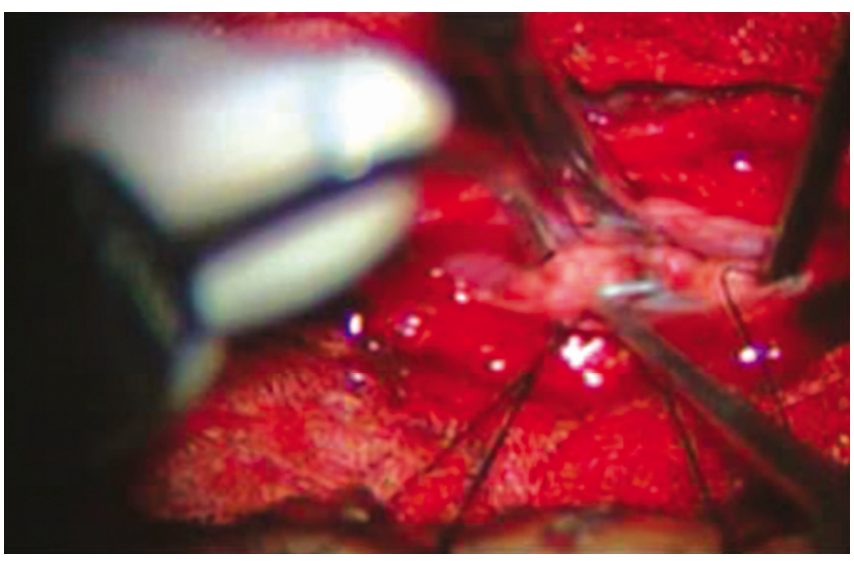

Fig. 5. Intraoperative photography is showing nerve root herniation through a dural defect (case 2). The nerve hook is using to reposition the incarcerated nerve root through ventral dural defect.

midline incision of the dorsal dura, incarcerated nerve root was repositioned and duroplasty was done. Postoperatively, the patient's sciatica was immediately alleviated and did not recur during 1-year follow-up period.

\section{DISCUSSION}

The spinal dura encloses the nerve roots and CSF. When the 2 layers of cranial dura enter the spinal canal, the outer layer blends with the periosteum of the cervical laminae within the canal, and the inner layer joins the arachnoid and becomes the spinal dura ${ }^{5)}$. Inner and outer surfaces of the spinal dura are covered by flattened fibroblasts, and the dense membrane is separated from the periosteum by a narrow epidural space ${ }^{10)}$. Because the spinal dura consists of the only inner membrane of 2 layers, compared with the cranial dura, it may be prone to tear and rupture. According to advances in instrumentation, surgeons get 
more aggressive attitudes toward spine surgery which could not be performed previously, and are likely to encounter increasing numbers of the dura tear. It is reported that the incidence of iatrogenic dural tears is about $0.3 \%-13 \%$, but varies according to the type of surgical procedure performed, repeated operation, lesion level, and use of instruments ${ }^{1,3,7,8,13-15}$. How does extradural incarceration of the spinal nerve root develop, even though no event intraoperatively? The acute pressure of the protruded disc may erode and then thin the dura ${ }^{6,9)}$. The existence of adhesions between the ventral dura and the posterior longitudinal ligament is likely to develop dural thinning and subsequent perforation $^{4,11)}$. This mechanical irritation and adhesion caused by disc inflammatory process may be predisposing factor to make dura thinning. Also, it must be considered intraoperative partial injury of the spinal dura in primary surgery.

To explain injury mechanism of ventral side dura, following theories are worth consideration. Spine surgeons remove ruptured disc particle after retraction of nerve root by using nerve hook or retractor. Ventral side dura layer might be trapped between retractor and dorsal surface of vertebral body, because dura is rolled to medial direction when dura retracted by nerve retractor. That is why caution is needed during nerve root manipulation. Another caution is using of pituitary forceps during removal of disc in disc space. When pituitary forceps go through into disc space, forceps should be closed, because opened forceps could damage to ventral dura during dura retraction.

After intraoperatively partial injury of the spinal dura, neither rupture of the arachnoid membrane and leakage of CSF occur, incidentally increased cerebrospinal pressure (e.g., coughing duration extubation) lead arachnoid membrane to bulge easily due to thin and delicate nature of the arachnoid membrane. The rupture of the arachnoid membrane causes leakage of the CSF postoperatively, and extradural herniation of nerve root occurs through this opening gradually. At this time, herniated nerve root has action of check valve and begins to swell and be incarcerated. If once swelling and incarceration of nerve root, patient suddenly complains of severe sciatica and motor weakness. In our case, direction of dura opening is all ventral to the dural sac. The authors think that incidental durotomy has to do with operative procedure. Pituitary forceps, root retractor and sharp suction tip worn off by drill are able to cause intraoperatively partial injury of the dura.

\section{CONCLUSION}

Incidental durotomy should be respected for its potential associated complications and medicolegal implications. The surgeons must be care of avoiding dura tear. When patient undertakes uncommon radiating pain and neurological deficit after lumbar discectomy, nerve root incarceration must be taken into consideration in the differential diagnosis.

\section{REFERENCES}

1. Black P: Cerebrospinal fluid leaks following spinal surgery: use of fat grafts for prevention and repair. Technical note. J Neurosurg 96(2 Suppl):250-252, 2002

2. Bosacco SJ, Gardner MJ, Guille JT: Evaluation and treatment of dural tears in lumbar spine surgery: a review. Clin Orthop Relat Res (389):238-247, 2001

3. Choe IS: Therapeutic results of CSF leakage due to unintended incidental durotomy in spine surgery. J Korean Neurosurg Soc 35: 574-578, 2004

4. Choi JY, Lee WS, Sung KH: Intradural lumbar disc herniation--is it predictable preoperatively? A report of two cases. Spine J 7:111117, 2007

5. Cohen MS, Wall EJ, Olmarker K, Rydevik BL, Garfin SR: Anatomy of the Spinal Nerve Roots in the Lumbar and Lower Thoracic Spine. in Rothman RH, Simeone FA (eds): The Spine, ed 4. Philadelphia (PA): Saunders, 1999, Vol 1, pp99-106

6. Dansy WE: Serious complications of ruptured intervertebral disks. JAMA 119:474-477, 1942

7. Hodges SD, Humphreys SC, Eck JC, Covington LA: Management of incidental durotomy without mandatory bed rest. A retrospective review of 20 cases. Spine (Phila Pa 1976) 24:2062-2064, 1999

8. Jones AA, Stambough JL, Balderston RA, Rothman RH, Booth RE Jr: Long-term results of lumbar spine surgery complicated by unintended incidental durotomy. Spine (Phila Pa 1976) 14:443-446, 1989

9. Koç RK, Akdemir H, Oktem IS, Menkü A: Intradural lumbar disc herniation: report of two cases. Neurosurg Rev 24:44-47, 2001

10. Parent A: Carpenter's Human Neuroanatomy, ed 9. Baltimore: Williams \& Wilkins, 1996

11. Reina EG, Calonge ER, Heriot RP: Transdural lumbar disc herniation. Spine (Phila Pa 1976) 19:617-619, 1994

12. Saxler G, Krämer J, Barden B, Kurt A, Pförtner J, Bernsmann K: The long-term clinical sequelae of incidental durotomy in lumbar disc surgery. Spine (Phila Pa 1976) 30:2298-2302, 2005

13. Smith MD, Bolesta MJ, Leventhal M, Bohlman HH: Postoperative cerebrospinal-fluid fistula associated with erosion of the dura. Findings after anterior resection of ossification of the posterior longitudinal ligament in the cervical spine. J Bone Joint Surg Am 74:270277, 1992

14. Tafazal SI, Sell PJ: Incidental durotomy in lumbar spine surgery: incidence and management. Eur Spine J 14:287-290, 2005

15. Wang JC, Bohlman HH, Riew KD: Dural tears secondary to operations on the lumbar spine. Management and results after a twoyear-minimum follow-up of eighty-eight patients. J Bone Joint Surg Am 80:1728-1732, 1998 